\title{
Effects of personality on overtime work: a cross-sectional pilot study among Japanese white-collar workers
}

\author{
Mitsuo Uchida*, Minoru Kaneko and Shigeyuki Kawa
}

\begin{abstract}
Background: As detailed associations between personality and long work hours are unclear, we assessed associations between personality dimensions and overtime work among Japanese white-collar workers.

Methods: From records of hours worked over 12 months by 267 office workers in an organization within the service industry, average overtime work hours per month and occurrence of excessive overtime was determined for each worker. Excessive overtime was defined as $>45$ overtime work hours per month for at least one month. Responses to a questionnaire assessing socio-demographic and workplace-related factors and the Big Five personality test were analyzed. Associations between personality factors and overtime work were assessed by multivariate logistic regression analysis.

Results: Low Extraversion was associated with excessive overtime work (OR 2.02, 95\% Cl $1.02-4.02, P=0.04)$.

Conclusions: It is suggested that workers with low Extraversion can't share work when busy to avoid excessive overtime. Personality factors should be considered in studies evaluating work time. Moreover, strengthening communication among workers with low Extraversion may reduce excessive overtime work and associated health problems.
\end{abstract}

Keywords: Big Five, Long work hours, Overtime work, Personality, White-collar workers

\section{Background}

Number of work hours is important in occupational health [1-3]. Long work hours are associated with adverse health effects, including cardiovascular disease [4-6], high blood pressure [7], mortality [8], and workrelated injuries [9]. These adverse effects are mainly caused by sleep loss and severe fatigue due to extended work hours $[10,11]$. Therefore, excessive work hours should be discouraged or limited to prevent adverse health effects.

As long work hours are thought to affect work-related diseases, official guidelines have been developed in Japan with the aim of preventing health problems due to long work hours [12]. Every year, the Ministry of Health Labour and Welfare releases data detailing industrial accidents [13] wherein we can see a relationship between

\footnotetext{
* Correspondence: uchida01@shinshu-u.ac.jp

Center for Health, Safety and Environmental Management, Shinshu University, 3-1-1 Asahi, Matsumoto 390-8621, Japan
}

long work hours and ill-health. These data show excessive work hours consistently associated with physical diseases such as cerebrovascular or cardiovascular diseases, but not with mental disorders. Several studies have been conducted to explore associations between long work hours and mental health, however, reviews show results were inconsistent and associations unclear $[14,15]$. This disparity may be because workers' mental health is affected by not only number of working hours but also their relationships at work [16], family factors [17] and individual factors [15]. The number of working hours, therefore, may be only one factor among several affecting workers' mental health and it is necessary to clarify the associations in detail.

In general, we see variation in number of working hours by occupation or workplace $[18,19]$. However, we might see this variation among workers at the same workplace doing the same job. Though this phenomenon occurs, few reports address the reasons based on scientific 
theory. Although some reports have shown work hour variation is related to workload [20,21], position [22], immersion $[23,24]$ or type A personality [6,25-27], there is little information relating number of working hours to occupational health. This paucity of information may be one reason why the association between number of work hours and mental health is unclear.

Personality is known to be an important factor in human behavior and mental health. Recently a significant body of literature has accumulated to support the five-factor theory of personality in which factors such as Extraversion or Conscientiousness have been shown to be associated with symptoms of depression [28-30], work performance $[31,32]$ or absenteeism of workers [33]. Therefore, personality factor is speculated to be also associated with number of working hours. However, as far as the authors are aware, there are no reports clarifying the association between Big Five personality and number of working hours. If Big Five personality factors are associated with number of working hours, particular personality characteristics may play important roles in the association between number of working hours and workers' mental health. Thus, personality of workers is thought to be fundamental information to understanding the association.

Before planning a study regarding number of working hours and workers mental health, we thought to clarify the association between personality and number of working hours. Therefore, the aim of this study is to examine which Big Five factors are related to long work hours. Moreover, findings of this study may inform construction of further measurements of long work hours. Thus, we conducted this pilot study to examine associations between workers' scores on the Big Five personality test and number of working hours.

\section{Methods}

\section{Subjects}

A total of 467 office workers employed in a service industry organization in August 2012 participated in this study. They worked during the day almost always seated at a personal computer, performing similar tasks such as making documents, responding to telephone calls, filing materials, and attending meetings. At the beginning of the study, leaflets explaining the study procedure were distributed to all workers. Written informed consent was obtained from all participants. All data were provided and analyzed anonymously. Of the 467 workers, 330 (70.7\%) completed the questionnaire. After excluding 31 workers for whom complete work hour information was unavailable, 18 higher level managers who did not record their work time, 8 workers with severe illnesses, and 6 workers who submitted incomplete questionnaires, 267 workers were enrolled (57.2\%). The study design and procedure were reviewed and approved by the
Committee for Medical Ethics of Shinshu University (approval number 1790).

\section{Questionnaires}

A self-administered questionnaire comprising items regarding socio-demographic factors, workplace-related factors, and Big Five personality factors was distributed to every participant. Participants completed and immediately returned the questionnaire in a sealed envelope. The questions were based on those in previous published reports $[20,24,34,35]$. Socio-demographic factors included sex (male, female), age (years), height $(\mathrm{cm})$, weight $(\mathrm{kg})$, average sleep per night (hours), drinking alcoholic beverages (every day, sometimes, occasionally, never), smoking (current smoker, ex-smoker, never smoker), physical exercise (every day, sometimes, occasionally, never), hobbies (yes, no), meal times (regular, irregular), current illness (yes, no), marital status (married, unmarried (including divorced or widowed)), educational level (postgraduate, graduate, graduate of junior college or technical training, no academic qualifications), stress at home (yes, no), and human relations at home (good, poor). Workplace-related factors included position within the company (manager or higher, assistant manager, chief, clerk, part-time worker) and commuting time (minutes). The factors also included job demand, decision latitude, and social support [36,37] according to the Japanese version of Brief Job Stress Questionnaire [38]. In addition, work-time related factors were assessed using the following negative and positive attitude questions. Negative factors: can you take paid holidays?; do you have an opportunity to stop work to go home?; do you have difficulty going home due to concern about other workers?; do you have a fear of the boss?: Positive factors: do you have work motivation?; do you have a work purpose?; do you have success motivation?; do you feel gratitude for your employment? These questions were also based on those in previous reports [20,24,34]. These factors were assessed on a 4-point Likert scale (ranging from a score of 4 for high and 1 for low). The internal consistencies (Cronbach's alpha) of the Negative and Positive attitude questions were 0.55 and 0.57 , respectively.

We assessed personality characteristics using the Big Five personality test [39], based on the five-factor model which is generally accepted worldwide. The model describes an individual's personality along five dimensions, Extraversion, Agreeableness, Conscientiousness, Emotional stability, and Openness. In this study, the Japanese version of the Big Five personality test [39] including 70 questions was applied. Scores for each characteristic range from 0 to 12 with 12 indicating a high degree of the characteristic. Scores were determined using Windows software accompanying the manual [39] and applied for analysis in this study. In this study, the internal consistencies (Cronbach's 
alpha) of Extraversion, Agreeableness, Conscientiousness, Emotional stability and Openness were found to be 0.90 , $0.76,0.84,0.91$ and 0.81 , respectively.

\section{Number of working hours}

In this sample, full-time workers were contracted to work from 08:30 to 17:15 daily with a $1 \mathrm{~h}$ lunch break amounting to a standard $7 \mathrm{~h} 45 \mathrm{~min} /$ day, $38 \mathrm{~h} 45 \mathrm{~min} /$ week and part-time workers were contracted to work a standard $30 \mathrm{~h} /$ week. The principal of the organization encouraged all workers to work a limited number of overtime hours. Additional work hours beyond the standard were counted as overtime work hours. All workers recorded their working time into their personal computers daily to be checked by their boss, thus allowing accurate determination of the number of hours worked by each subject. Such data recorded for the previous 12 months were obtained and used in this study.

As adverse health effects can be caused by not only permanent long work hours but also accumulation of overtime hours within a short period [12], two outcome measures were employed to evaluate number of working hours. First, average number of overtime work hours, calculated as the average of 12 months of overtime for each worker and expressed as "hours per month", and second, excessive overtime work. In Japan, workers can work overtime by either working beyond the set number of hours per day or by working on their scheduled day off, to a maximum of $45 \mathrm{~h} /$ month, as prescribed by labor-management agreements; if these agreements include special clauses, workers can work more than this upper limit [40]. Consequently, all workers are aware of their upper limit for overtime work hours, therefore, it is important to know whether workers breach the limit or not when evaluating long work hours. In this study, excessive overtime work was defined as that exceeding $45 \mathrm{~h} /$ month at least once during the previous 12 months.

\section{Statistical analysis}

Participants were divided into 4 groups by age $(20-29$, $30-39,40-49, \geq 50$ years), 3 by BMI $(<18.5,18.5-$ $25, \geq 25$ ), and 4 by work status (Assistant manager or higher, Chief, Clerk, Part-time worker). Other factors were dichotomized (yes/no, Likert scale $1-2 / 3-4$ or suitable division according to preliminary calculations). In this study, each personality factor was dichotomized by median score into high-score group or low-score group to determine whether high personality score group did more overtime work than low personality score group or otherwise, respectively. Average numbers of overtime work hours were similarly treated with participants classified as long overtime work group or short overtime work group according to median overtime work hours. Subjects were classified as excessive overtime work occurrence group if they worked overtime beyond $45 \mathrm{~h} /$ month at least once during 12 months or excessive overtime work nonoccurrence group if they did not. For statistical analysis, univariate and multivariate logistic regression models were used. First, a univariate regression model of sociodemographic and workplace-related factors for the two outcome measures were used as preliminary analysis. Subsequently, significant factors which were observed in the first step were used as adjusting factors for a multivariate regression model, and associations between the Big Five personality factors and the two outcome measures were evaluated. All dimensions of personality factors were analyzed independently to avoid overadjustment [33]. Associations were expressed as odds ratios (OR) and 95\% confidence interval $(95 \% \mathrm{CI})$. PASW 18.0 software (SPSS Inc., Chicago, IL) was used for all analyses, and $P<0.05$ was taken to indicate statistical significance.

\section{Results}

Table 1 shows details of the participants who comprised 142 male and 125 female workers, with most (38.2\%) aged $30-39$ years old. Participants worked a mean \pm SD of $17.8 \pm 13.0$ overtime work hours per month over 12 months, with a median of $16 \mathrm{~h}$ (range $1.0-66.1 \mathrm{~h}$ ). Workers were dichotomized into long overtime work group and short overtime work group 50\% each according to the median $(16 \mathrm{~h})$ overtime work hours. Seventy-four participants $(27.7 \%)$ worked excessive overtime at least once during the previous 12 months. Table 2 shows the descriptive of the Big Five personality factors of participants. The scores were not distributed normally and the median scores were used to divide responses into two groups.

Table 3 shows the univariate logistic regression model with, 8 factors, sex, BMI, meal times, position, job demand, taking paid holiday, stopping work, and fear of the boss that were significantly associated with both of the two outcome measures. In addition, 4 factors, age, marital status, decision latitude and difficulty going home were significantly associated with one of the two outcome measures. Four personality factors, Extraversion, Agreeableness, Conscientiousness and Emotional stability were significantly associated with excessive overtime work in this univariate model.

Table 4 shows associations between personality and long overtime work hours and excessive overtime work. Twelve factors found significant in the univariate model plus the social support factor which is usually employed in occupational health surveys, comprised the 13 factors used as adjusting factors. We made correlation matrices within the Big Five personality factors and these 13 factors and no multicollinearity was found among them (the largest correlation was found between Emotional 
Table 1 Socio-demographic and workplace-related factors of the study population

\begin{tabular}{|c|c|c|c|}
\hline Factor & Classification & $n=267$ & $\%$ \\
\hline \multicolumn{4}{|l|}{ Socio-demographic factors } \\
\hline \multirow[t]{2}{*}{ Sex } & Male & 142 & 53.2 \\
\hline & Female & 125 & . \\
\hline \multirow[t]{4}{*}{ Age } & $20-29$ & 35 & 13.1 \\
\hline & $30-39$ & 102 & \\
\hline & $40-49$ & 76 & 28. \\
\hline & $50-$ & 54 & 0 \\
\hline \multirow[t]{3}{*}{ BMI } & $<18.5$ & 32 & 12. \\
\hline & $18.5-25$ & 186 & 9.7 \\
\hline & $\geq 25$ & 49 & 10.4 \\
\hline \multirow[t]{2}{*}{ Sleep } & $<6$ hours & 37 & 13. \\
\hline & $\geq 6$ hours & 230 & 86.1 \\
\hline \multirow[t]{2}{*}{ Drinking } & Never or occasionally & 170 & 63.7 \\
\hline & Sometimes or more often & 97 & 36.3 \\
\hline \multirow[t]{2}{*}{ Smoking } & Never or ex-smoker & 226 & 84.6 \\
\hline & Current smoker & 41 & 15. \\
\hline \multirow[t]{2}{*}{ Physical exercise } & Never or occasionally & 121 & 45. \\
\hline & Sometimes or more often & 146 & 54. \\
\hline \multirow[t]{2}{*}{ Hobbies } & Yes & 184 & \\
\hline & No & 83 & 31. \\
\hline \multirow[t]{2}{*}{ Meal times } & Regular & 232 & 86. \\
\hline & Irregular & 35 & 3. \\
\hline \multirow[t]{2}{*}{ Current illness } & Yes & 67 & 5. \\
\hline & No & 200 & \\
\hline \multirow[t]{2}{*}{ Marital status } & Married & 174 & 5.8 \\
\hline & Unmarried & 93 & 3 \\
\hline \multirow[t]{2}{*}{ Educational level } & Graduate or higher & 139 & 32. \\
\hline & Under graduate & 128 & \\
\hline \multirow[t]{2}{*}{ Stress at home } & Yes & 103 & 38. \\
\hline & No & 164 & 61. \\
\hline \multirow[t]{2}{*}{$\begin{array}{l}\text { Human relations at } \\
\text { home }\end{array}$} & Good & 242 & 0. \\
\hline & Poor & 25 & \\
\hline
\end{tabular}

Workplace-related factors

Position

Commuting time

Job demand

$\begin{array}{ccc}\begin{array}{c}\text { Assistant manager or } \\ \text { higher } \\ \text { Chief }\end{array} & 23 & 8.6 \\ \text { Clerk } & 69 & 25.8 \\ \text { Part-time worker } & 84 & 35.2 \\ <30 \text { minutes } & 178 & 30.3 \\ \geq 30 \text { minutes } & 89 & 33.3 \\ \text { High } & 179 & 67.0 \\ \text { Low } & 88 & 33.0\end{array}$

Table 1 Socio-demographic and workplace-related factors of the study population (Continued)

\begin{tabular}{llcc} 
Decision latitude & High & 231 & 86.5 \\
Social support & Low & 36 & 13.5 \\
Taking paid holiday & Low & 196 & 73.4 \\
Stopping work & Yes & 218 & 26.6 \\
& No & 49 & 18.4 \\
Difficulty going home & Yes & 102 & 38.2 \\
Fear of the boss & No & 165 & 61.8 \\
Yes & 55 & 20.6 \\
Work motivation & No & 212 & 79.4 \\
Work purpose & Yes & 59 & 22.1 \\
& No & 208 & 77.9 \\
Success motivation & Yes & 226 & 84.6 \\
Gratitude for & No & 41 & 15.4 \\
employment & Yes & 213 & 79.8 \\
& No & 54 & 20.2 \\
& Yes & 54 & 20.2 \\
& No & 213 & 79.8 \\
& Yes & 226 & 84.6 \\
& & 41 & 15.4 \\
\hline
\end{tabular}

stability and fear of the boss; $r=-0.24)$. Extraversion was found to be significantly associated with excessive overtime work (OR 2.02, 95\%CI $1.02-4.02, P=0.04$ ), whereas the other four Big Five personality factors showed no associations in either model.

\section{Discussion}

In this pilot study, associations between the Big Five personality factors and long overtime work hours and

Table 2 Descriptive of the Big Five personality factors for the study population

\begin{tabular}{lll}
\hline Big Five personality factors & & \\
\hline Extraversion & 4.4 & \pm 4.0 \\
Agreeableness & 3 & $(0-12)$ \\
& 8.7 & \pm 2.6 \\
Conscientiousness & 9 & $(0-12)$ \\
& 6.5 & \pm 3.5 \\
Emotional stability & 7 & $(0-12)$ \\
& 5.7 & \pm 4.2 \\
Openness & 5 & $(0-12)$ \\
& 3.7 & \pm 3.1 \\
\hline Personality factor scores and overtime work hours are shown as mean \pm SD \\
and median (range).
\end{tabular}


Table 3 Results of univariate logistic regression analysis for long overtime work hours and excessive overtime work

\begin{tabular}{|c|c|c|c|c|c|c|c|c|c|}
\hline \multirow{2}{*}{$\begin{array}{l}\text { Factor } \\
\text { Socio-demographic factors }\end{array}$} & \multirow[t]{2}{*}{ Classification } & \multicolumn{4}{|c|}{ Long overtime work hours } & \multicolumn{4}{|c|}{ Excessive overtime work } \\
\hline & & OR & \multicolumn{2}{|c|}{$95 \% \mathrm{Cl}$} & $P$ & OR & \multicolumn{2}{|c|}{$95 \% \mathrm{Cl}$} & $P$ \\
\hline \multirow[t]{2}{*}{ Sex } & Male & 1.00 & & & & 1.00 & & & \\
\hline & Female & 0.18 & 0.10 & 0.30 & $<0.01$ & 0.26 & 0.14 & 0.47 & $<0.01$ \\
\hline \multirow[t]{4}{*}{ Age } & $20-29$ & 1.00 & & & & 1.00 & & & \\
\hline & $30-39$ & 0.67 & 0.31 & 1.45 & 0.31 & 0.69 & 0.31 & 1.52 & 0.35 \\
\hline & $40-49$ & 0.57 & 0.25 & 1.28 & 0.17 & 0.31 & 0.13 & 0.76 & 0.01 \\
\hline & $50-$ & 0.69 & 0.29 & 1.64 & 0.40 & 0.58 & 0.23 & 1.42 & 0.23 \\
\hline \multirow[t]{3}{*}{ BMI } & $18.5-25$ & 1.00 & & & & 1.00 & & & \\
\hline & $<18.5$ & 0.65 & 0.30 & 1.40 & 0.27 & 0.66 & 0.26 & 1.71 & 0.40 \\
\hline & $\geq 25$ & 2.22 & 1.15 & 4.32 & 0.02 & 1.98 & 1.03 & 3.83 & 0.04 \\
\hline \multirow[t]{2}{*}{ Sleep } & $\geq 6$ hours & 1.00 & & & & 1.00 & & & \\
\hline & $<6$ hours & 0.92 & 0.46 & 1.85 & 0.82 & 1.72 & 0.83 & 3.57 & 0.14 \\
\hline \multirow[t]{2}{*}{ Drinking } & Never or occasionally & 1.00 & & & & 1.00 & & & \\
\hline & Sometimes or more often & 0.95 & 0.57 & 1.56 & 0.83 & 0.86 & 0.49 & 1.51 & 0.59 \\
\hline \multirow[t]{2}{*}{ Smoking } & Never or ex-smoker & 1.00 & & & & 1.00 & & & \\
\hline & Current smoker & 1.48 & 0.75 & 2.90 & 0.26 & 1.09 & 0.53 & 2.28 & 0.81 \\
\hline \multirow[t]{2}{*}{ Physical exercise } & Sometimes or more often & 1.00 & & & & 1.00 & & & \\
\hline & Never or occasionally & 0.84 & 0.52 & 1.36 & 0.47 & 1.12 & 0.65 & 1.91 & 0.69 \\
\hline \multirow[t]{2}{*}{ Hobbies } & Yes & 1.00 & & & & 1.00 & & & \\
\hline & No & 1.01 & 0.60 & 1.70 & 0.96 & 0.92 & 0.51 & 1.64 & 0.77 \\
\hline \multirow[t]{2}{*}{ Meal times } & Regular & 1.00 & & & & 1.00 & & & \\
\hline & Irregular & 3.91 & 1.71 & 8.97 & $<0.01$ & 3.82 & 1.84 & 7.94 & $<0.01$ \\
\hline \multirow[t]{2}{*}{ Current illness } & No & 1.00 & & & & 1.00 & & & \\
\hline & Yes & 0.68 & 0.39 & 1.19 & 0.18 & 0.55 & 0.28 & 1.08 & 0.08 \\
\hline \multirow[t]{2}{*}{ Marital status } & Married & 1.00 & & & & 1.00 & & & \\
\hline & Unmarried & 1.32 & 0.79 & 2.18 & 0.29 & 1.78 & 1.03 & 3.09 & 0.04 \\
\hline \multirow[t]{2}{*}{ Educational level } & Graduate or higher & 1.00 & & & & 1.00 & & & \\
\hline & Undergraduate & 0.74 & 0.46 & 1.20 & 0.22 & 0.66 & 0.38 & 1.14 & 0.14 \\
\hline Stress at home & No & 1.00 & & & & 1.00 & & & \\
\hline & Yes & 0.65 & 0.39 & 1.06 & 0.08 & 0.88 & 0.51 & 1.54 & 0.66 \\
\hline Human relations at home & Good & 1.00 & & & & 1.00 & & & \\
\hline & Poor & 0.90 & 0.39 & 2.05 & 0.80 & 1.25 & 0.52 & 3.05 & 0.62 \\
\hline Workplace-related factors & & & & & & & & & \\
\hline Position & Clerk & 1.00 & & & & 1.00 & & & \\
\hline & Chief & 0.92 & 0.35 & 2.41 & 0.87 & 0.83 & 0.33 & 2.11 & 0.70 \\
\hline & Assistant manager or higher & 1.12 & 0.58 & 2.20 & 0.73 & 0.61 & 0.32 & 1.16 & 0.13 \\
\hline & Part-time worker & 0.05 & 0.02 & 0.13 & $<0.01$ & 0.03 & 0.01 & 0.14 & $<0.01$ \\
\hline Commuting time & $<30$ minutes & 1.00 & & & & 1.00 & & & \\
\hline & $\geq 30$ minutes & 0.80 & 0.48 & 1.33 & 0.39 & 0.80 & 0.45 & 1.42 & 0.44 \\
\hline Job demand & Low & 1.00 & & & & 1.00 & & & \\
\hline & High & 3.15 & 1.84 & 5.41 & $<0.01$ & 2.67 & 1.39 & 5.11 & $<0.01$ \\
\hline Decision latitude & High & 1.00 & & & & 1.00 & & & \\
\hline & Low & 1.90 & 0.92 & 3.93 & 0.08 & 2.08 & 1.01 & 4.30 & 0.048 \\
\hline
\end{tabular}


Table 3 Results of univariate logistic regression analysis for long overtime work hours and excessive overtime work (Continued)

\begin{tabular}{|c|c|c|c|c|c|c|c|c|c|}
\hline \multirow[t]{2}{*}{ Social support } & High & 1.00 & & & & 1.00 & & & \\
\hline & Low & 1.28 & 0.74 & 2.21 & 0.37 & 1.63 & 0.91 & 2.93 & 0.10 \\
\hline \multirow[t]{2}{*}{ Taking paid holiday } & Yes & 1.00 & & & & 1.00 & & & \\
\hline & No & 5.01 & 2.38 & 10.55 & $<0.01$ & 4.47 & 2.33 & 8.54 & $<0.01$ \\
\hline \multirow[t]{2}{*}{ Stopping work } & No & 1.00 & & & & 1.00 & & & \\
\hline & Yes & 2.42 & 1.45 & 4.02 & $<0.01$ & 1.97 & 1.14 & 3.40 & 0.01 \\
\hline \multirow[t]{2}{*}{ Difficulty going home } & No & 1.00 & & & & 1.00 & & & \\
\hline & Yes & 3.32 & 1.73 & 6.37 & $<0.01$ & 1.85 & 0.99 & 3.47 & 0.05 \\
\hline \multirow[t]{2}{*}{ Fear of the boss } & No & 1.00 & & & & 1.00 & & & \\
\hline & Yes & 2.09 & 1.15 & 3.81 & 0.02 & 2.63 & 1.43 & 4.82 & $<0.01$ \\
\hline \multirow[t]{2}{*}{ Work motivation } & Yes & 1.00 & & & & 1.00 & & & \\
\hline & No & 1.31 & 0.67 & 2.56 & 0.43 & 1.26 & 0.61 & 2.58 & 0.54 \\
\hline \multirow[t]{2}{*}{ Work purpose } & Yes & 1.00 & & & & 1.00 & & & \\
\hline & No & 0.98 & 0.54 & 1.78 & 0.95 & 1.40 & 0.74 & 2.67 & 0.30 \\
\hline \multirow[t]{2}{*}{ Success motivation } & Yes & 1.00 & & & & 1.00 & & & \\
\hline & No & 0.58 & 0.31 & 1.07 & 0.08 & 0.89 & 0.46 & 1.72 & 0.73 \\
\hline \multirow[t]{2}{*}{ Gratitude for employment } & Yes & 1.00 & & & & 1.00 & & & \\
\hline & No & 0.93 & 0.48 & 1.80 & 0.82 & 0.59 & 0.26 & 1.34 & 0.21 \\
\hline \multicolumn{10}{|l|}{ Big Five personality factors } \\
\hline \multirow[t]{2}{*}{ Extraversion } & High & 1.00 & & & & 1.00 & & & \\
\hline & Low & 1.57 & 0.97 & 2.55 & 0.07 & 3.07 & 1.73 & 5.45 & $<0.01$ \\
\hline \multirow[t]{2}{*}{ Agreeableness } & High & 1.00 & & & & 1.00 & & & \\
\hline & Low & 1.35 & 0.83 & 2.19 & 0.22 & 2.06 & 1.18 & 3.61 & 0.01 \\
\hline \multirow[t]{2}{*}{ Conscientiousness } & High & 1.00 & & & & 1.00 & & & \\
\hline & Low & 1.27 & 0.78 & 2.06 & 0.33 & 1.75 & 1.01 & 3.05 & 0.047 \\
\hline \multirow[t]{2}{*}{ Emotional stability } & High & 1.00 & & & & 1.00 & & & \\
\hline & Low & 1.48 & 0.91 & 2.40 & 0.11 & 2.49 & 1.42 & 4.37 & $<0.01$ \\
\hline \multirow[t]{2}{*}{ Openness } & High & 1.00 & & & & 1.00 & & & \\
\hline & Low & 1.23 & 0.76 & 2.00 & 0.39 & 1.36 & 0.79 & 2.35 & 0.26 \\
\hline
\end{tabular}

excessive overtime were evaluated among Japanese white-collar workers. Low Extraversion was found to be associated with excessive overtime work, while it had no significant association with long overtime work hours.

We employed the globally accepted Big Five personality test [39] to evaluate the characteristics of workers in this study. Although previous studies showed associations between Extraversion and work performance of workers [32] or absenteeism [33], there have been no previous studies regarding the association with number of working hours. The results of the present study indicated that low Extraversion was related to excessive overtime in workers in both univariate and multivariate regression models. The association was significant for excessive overtime work but not daily longer overtime work hours. Extraversion generally indicates a personality that displays behaviors of talkativeness, liveliness or proactivity [39]. We therefore speculate that the present findings could be explained to the extent that workers with the characteristic of low Extraversion may tend to work alone even when they become busy, which may result in excessive overtime work as their work burden increases. In addition to this result, a previous review [28] and other studies [29,30] showed an association between lower Extraversion and depressive symptoms. From these results, low Extraversion may be associated with both excessive overtime and symptoms of depression. The present study may therefore be useful to inform the relationship among number of working hours and mental health. As Conscientiousness was also shown to be related to high work performance [31], we initially expected that this characteristic would be associated with overtime work, but no such association was found in the multivariate analysis. The absence of this association could be explained that conscientious workers may tend to 
Table 4 Odds ratios (OR), $95 \%$ confidence intervals $(95 \% \mathrm{Cl})$ and significance of personality factors for belonging to the group with long overtime work hours and excessive overtime work

\begin{tabular}{|c|c|c|c|c|c|c|c|c|c|}
\hline \multirow[t]{2}{*}{ Personality factor } & & \multicolumn{4}{|c|}{ Long overtime work hours } & \multicolumn{4}{|c|}{ Excessive overtime work } \\
\hline & & $\frac{\text { OR }}{1.00}$ & \multicolumn{2}{|c|}{$95 \% \mathrm{Cl}$} & $P$ & $\begin{array}{c}\text { OR } \\
1.00\end{array}$ & \multicolumn{2}{|c|}{$95 \% \mathrm{Cl}$} & $P$ \\
\hline & Low & 0.88 & 0.46 & 1.68 & 0.70 & 2.02 & 1.02 & 4.02 & 0.04 \\
\hline \multirow[t]{2}{*}{ Agreeableness } & High & 1.00 & & & & 1.00 & & & \\
\hline & Low & 0.83 & 0.43 & 1.58 & 0.57 & 1.69 & 0.85 & 3.36 & 0.13 \\
\hline \multirow[t]{2}{*}{ Conscientiousness } & High & 1.00 & & & & 1.00 & & & \\
\hline & Low & 0.94 & 0.48 & 1.84 & 0.85 & 1.51 & 0.75 & 3.06 & 0.25 \\
\hline \multirow[t]{2}{*}{ Emotional stability } & High & 1.00 & & & & 1.00 & & & \\
\hline & Low & 0.66 & 0.34 & 1.28 & 0.22 & 1.54 & 0.77 & 3.06 & 0.22 \\
\hline \multirow[t]{2}{*}{ Openness } & High & 1.00 & & & & 1.00 & & & \\
\hline & Low & 0.75 & 0.38 & 1.50 & 0.42 & 1.14 & 0.56 & 2.33 & 0.72 \\
\hline
\end{tabular}

Each personality factor was adjusted for any socio-demographic factor or work-place related factor significant in univariate model. Adjusted factors were sex, age, BMI, meal times, marital status, position, job demand, decision latitude, social support, taking paid holidays, stopping work, difficulty going home and fear of the boss.

rigidly follow the rules regarding the number of permissible overtime working hours. An individual with the Conscientiousness personality trait not only performs his/her work conscientiously but also behaves honestly. Agreeableness, Emotional stability and Openness were found to be associated with depressive symptoms in other studies $[29,30]$. In this study, Agreeableness and Emotional stability were associated with excessive overtime work in the univariate analysis, but this association was not evident in the multivariate analysis. This phenomenon indicated that low association may exist between Agreeableness and Emotional stability and excessive overtime work in univariate analysis. But those associations disappeared by adjustment in multivariate analysis because some confounding variables might exist between Agreeableness and Emotional stability and excessive overtime work. In other words, perhaps these particular personality factors may associate with mental health directly rather than excessive overtime work. However, these possibilities are not explained by this study alone, further study is needed to clarify associations between number of working hours and mental health. Overall, this study showed that excessive overtime work was most associated with Extraversion among Big Five factors. We propose that Extraversion should be taken into consideration preferentially to control overtime work. For example, if we devise practical ways to enhance communication among workers or train them in communication skills it may induce sharing of heavy workloads resulting in reduction of excessive overtime work in individuals during busy periods. Moreover, this intervention may contribute to improvement of workers' mental health.

Although personality can be expected to affect work time, there have been few reports regarding this association. However, as number of work hours is known to be a key factor in adverse health effects, it is necessary to discuss these associations. The lack of reports is probably due to the absence of accurate work time data because previous studies used self-reported number of work hours and average number of hours per day $[6,27]$. Therefore, accurate data regarding overtime work hours throughout the year could not be considered. This important issue was noted as a problem that should be clarified in a previous report [14]. In the present study, we used precise work hour data and evaluated the association with personality because we used work time records. Moreover, this study suggested that excessive overtime is a useful factor for work time analysis that can also be measured as accumulation of number of working hours over short periods. Therefore, this outcome measure allowed the evaluation of more information than just average number of work hours. Thus, it was suggested that not only average number of work hours but also occurrence of excessive overtime work should be taken into consideration to evaluate work time effects.

This study had several limitations. First, because this pilot study was cross-sectional, cause-effect relations were less clear than had it been longitudinal. In addition, time-course change of the relations between variables and number of working hours was also unclear. Because time-course change of the variables may affect the association between personality and number of working hours, a longitudinal study will be necessary. Second, the alpha of the work-time related questionnaire was not high although the questions were based on those validated in previous studies. This may be because the questionnaire included some questions which were not entirely associated with number of working hours. Improvement of the questionnaire is a task for the future. 
Third, to the extent that the sample size was relatively small and drawn from white-collar workers at one institution it may have influenced the skewness or distribution of the personality scores. Indeed, some employers screen and select employees that fit a prescribed or desired personality profile deemed most suitable for their organization, which would explain any skew in distribution of personality scores. In addition a larger sample from a wider occupation population might have allowed us to evaluate extremely excessive overtime work such as over $80 \mathrm{~h} /$ month or $100 \mathrm{~h} /$ month. Further studies in larger numbers of subjects across a wider range of occupations are necessary to fully generalize the results. Moreover, selection bias may have occurred because those that worked longer work hours may have been suspicious and chosen not to participate. Response rates should be increased in future studies to avoid such bias. Fourth, the possibility of underestimation of number of working hours could not be fully ruled out. In Japan, work hours data from Labour Force Survey [18] is usually slightly larger than that from Monthly Labour Survey [19]. This disparity may be due to unpaid overtime work because the latter was derived from company data. More precise methods to investigate number of working hours should be determined. As issues remain unclear in this field, further studies in several disciplines are necessary.

\section{Conclusion}

The results of the present pilot study indicate low Extraversion is associated with excessive overtime work. We suggest personality factors should be included in studies which evaluate number of working hours and mental health. Moreover, strengthening communication skills or training workers in skills comprising Extraversion factors may contribute to reduction of excessive overtime work in individuals resulting in positive health benefits. Further studies are needed to clarify associations among personality, long work hours, and mental health among workers.

\section{Competing interests}

The authors declare that they have no competing interests.

\section{Authors' contributions}

MU contributed the study design, data collection, analysis, interpretation, and manuscript preparation. MK and SK helped with manuscript preparation and interpretation. All authors read and approved the final version of the manuscript.

\section{Acknowledgments}

We thank Tomoko Fujimura, Hiroko Hayashi, Naomi Yuzawa, Hiromi Saguchi, Koji Kamijo, Kazuki Nagai, Junichi Kitamura, and Yoshinobu Shinkai for their support.

Received: 30 April 2013 Accepted: 22 March 2014

Published: 27 March 2014

\section{References}

1. Working time. [http://www.ilo.org/empent/areas/business-helpdesk/ WCMS_DOC_ENT_HLP_TIM_EN/lang-en/index.htm]

2. Stress at the workplace. [http://www.who.int/occupational_health/topics/ stressatwp/en/]

3. Hurrell JJ Jr, McLaney MA: Exposure to job stress-a new psychometric instrument. Scand J Work Environ Health 1988, 14:27-28.

4. Uehata T: Long working hours and occupational stress-related cardiovascular attacks among middle-aged workers in Japan. $J$ Hum Ergol (Tokyo) 1991, 20:147-153.

5. Sokejima S, Kagamimori S: Working hours as a risk factor for acute myocardial infarction in Japan: case-control study. BMJ 1998, 317:775-780.

6. Virtanen M, Ferrie JE, Singh-Manoux A, Shipley MJ, Vahtera J, Marmot MG, Kivimaki M: Overtime work and incident coronary heart disease: the Whitehall II prospective cohort study. Eur Heart J 2010, 31:1737-1744.

7. Hayashi T, Kobayashi Y, Yamaoka K, Yano E: Effect of overtime work on 24-hour ambulatory blood pressure. J Occup Environ Med 1996, 38:1007-1011.

8. Nylen L, Voss M, Floderus B: Mortality among women and men relative to unemployment, part time work, overtime work, and extra work: a study based on data from the Swedish twin registry. Occup Environ Med 2001, 58:52-57.

9. Dembe AE, Erickson JB, Delbos RG, Banks SM: The impact of overtime and long work hours on occupational injuries and illnesses: new evidence from the United States. Occup Environ Med 2005, 62:588-597.

10. Krueger GP: Sustained work, fatigue, sleep loss and performance: a review of the issues. Work Stress 1989, 3:129-141.

11. Harma M: Workhours in relation to work stress, recovery and health. Scand J Work Environ Health 2006, 32:502-514.

12. Comprehensive Program for the Prevention of Health Impairment Due to Overwork; 2002 [http://www.jniosh.go.jp/icpro/jicosh-old/english/guideline/ OverworkMeasures.html]

13. Report of compensation for industrial accidents in 2011. [http://www. mhlw.go.jp/stf/houdou/2r9852000002coxc.html]

14. Fujino $Y$, Horie $S$, Hoshuyama T, Tsutsui T, Tanaka Y: A systematic review of working hours and mental health burden. Sangyo Eiseigaku Zasshi 2006, 48:87-97 (in Japanese)

15. Shima S: Overwork and mental health focusing on long working hours. Occup Health Rev 2008, 20:161-173 (in Japanese)

16. A survey on state of employees' health 2007. [http://www.mhlw.go.jp/ toukei/itiran/roudou/saigai/anzen/kenkou07/index.html]

17. Hammer TH, Saksvik PO, Nytro K, Torvatn H, Bayazit M: Expanding the psychosocial work environment: workplace norms and work-family conflict as correlates of stress and health. J Occup Health Psychol 2004, 9:83-97.

18. Labour force survey. [http://www.stat.go.jp/data/roudou/index.htm]

19. Monthly labour survey. [http://www.mhlw.go.jp/toukei/list/30-1a.html]

20. Shimomitsu T, Levi L: Recent working life changes in Japan. Eur J Public Health 1992, 2:76-86.

21. Kobayashi F: Japanese perspective of future worklife. Scand J Work Environ Health 1997, 23:66-72.

22. Brett JM, Stroh LK: Working 61 plus hours a week: why do managers do it? J Appl Psychol 2003, 88:67-78.

23. Akerstedt T, Knutsson A, Westerholm P, Theorell T, Alfredsson L, Kecklund G: Mental fatigue, work and sleep. J Psychosom Res 2004, 57:427-433.

24. Beckers DG, van der Linden D, Smulders PG, Kompier MA, van Veldhoven MJ, van Yperen NW: Working overtime hours: relations with fatigue, work motivation, and the quality of work. J Occup Environ Med 2004, 46:1282-1289.

25. Rhoads JM: Overwork. JAMA 1977, 237:2615-2618.

26. Watanabe S, Torii J, Shinkai S, Watanabe T: Relationships between health status and working conditions and personalities among VDT workers. Environ Res 1993, 61:258-265.

27. Hagihara A, Tarumi K, Miller AS, Morimoto K: Type A and Type B behaviors, work stressors, and social support at work. Prev Med 1997, 26:486-494.

28. Clark LA, Watson D, Mineka S: Temperament, personality, and the mood and anxiety disorders. J Abnorm Psychol 1994, 103:103-116.

29. Kling KC, Ryff CD, Love G, Essex M: Exploring the influence of personality on depressive symptoms and self-esteem across a significant life transition. J Pers Soc Psychol 2003, 85:922-932.

30. Chioqueta A, Sitiles T: Personality traits and the development of depression, hopelessness, and suicide ideation. Pers Individ Dif 2005, 38:1283-1291. 
31. Higgins DM, Peterson JB, Pihl RO, Lee AG: Prefrontal cognitive ability, intelligence, Big Five personality, and the prediction of advanced academic and workplace performance. J Pers Soc Psychol 2007, 93:298-319.

32. Thoresen CJ, Bradley JC, Bliese PD, Thoresen JD: The big five personality traits and individual job performance growth trajectories in maintenance and transitional job stages. J Appl Psychol 2004, 89:835-853.

33. Vlasveld MC, van der Feltz-Cornelis CM, Anema JR, van Mechelen W, Beekman AT, van Marwijk HW, Penninx BW: The associations between personality characteristics and absenteeism: a cross-sectional study in workers with and without depressive and anxiety disorders. J Occup Rehabil. in press.

34. Kawakami N, Araki S, Haratani T, Hemmi T: Relations of work stress to alcohol use and drinking problems in male and female employees of a computer factory in Japan. Environ Res 1993, 62:314-324.

35. van der Hulst M: Long workhours and health. Scand J Work Environ Health 2003, 29:171-188.

36. Karasek R: Job demands, job decision latitude and mental strain: implications for job redesign. Adm Sci Q 1979, 24:285-308.

37. Johnson JV, Hall EM: Job strain, work place social support, and cardiovascular disease: a cross-sectional study of a random sample of the Swedish working population. Am J Public Health 1988, 78:1336-1342.

38. Brief Job Stress Questionnaire mannual. [http://www.tmu-ph.ac/topics/ stress_table.php]

39. Murakami Y, Murakami C: BigFive Handbook 2nd Edition. Tokyo: Gakugeitosho; 2008

40. The Labor Standards Act. [http://law.e-gov.go.jp/htmldata/S22/S22HO049.html]

doi:10.1186/1756-0500-7-180

Cite this article as: Uchida et al:: Effects of personality on overtime work: a cross-sectional pilot study among Japanese white-collar workers. BMC Research Notes 2014 7:180.

\section{Submit your next manuscript to BioMed Central and take full advantage of:}

- Convenient online submission

- Thorough peer review

- No space constraints or color figure charges

- Immediate publication on acceptance

- Inclusion in PubMed, CAS, Scopus and Google Scholar

- Research which is freely available for redistribution 